\title{
Baer-Galois connections and applications
}

\section{GABRIELA OLTEANU}

\section{ABSTRACT.}

We define Baer-Galois connections between bounded modular lattices. We relate them to lifting lattices and we show that they unify the theories of (relatively) Baer and dual Baer modules.

Acknowledgements. This research is partially supported by the grants PN-II-RU-TE2009-1-303 and PN-II-ID-PCE-2012-4-0100.

\section{REFERENCES}

[1] Albu, T. and Năstăsescu, C., Relative finiteness in module theory, Marcel Dekker, 1984

[2] Amini, B., Ershad, M. and Sharif, H., Coretractable modules, J. Aust. Math. Soc., 86 (2009), 289-304

[3] Clark, J., Lomp, C., Vanaja, N. and Wisbauer, R., Lifting modules, Frontiers in Mathematics, Birkhäuser, 2006

[4] Crivei, S., Essential and retractable Galois connections, J. Algebra Appl., 12 (2013), 1350017 (14 pages)

[5] Crivei, S., Inankıl, H., Koşan, M. T., and Olteanu, G., Correspondences of coclosed submodules, Comm. Algebra, 41 (2013), 3635-3647

[6] Crivei, S. and Olteanu, G., GAP algorithms for finite abelian groups and applications, Carpathian J. Math., 24 (2008), 310-316

[7] Crivei, S. and Şuteu Szöllősi, Ş., Subgroup lattice algorithms related to extending and lifting abelian groups, Int. Electron. J. Algebra, 2 (2007), 54-70

[8] Dung, N. V., Huynh, D. V., Smith, P. F. and Wisbauer, R., Extending modules, Pitman Research Notes, 313, Longman Scientific and Technical, 1994

[9] Erné, M., Koslowski, J., Melton, A. and Strecker, G. E., A primer on Galois connections, in Proceedings of the 1991 Summer Conference on General Topology and Applications in Honor of Mary Ellen Rudin and Her Work, Annals of the New York Academy of Sciences, 704, 1993, pp. 103-125

[10] Grzeszczuk, P. and Puczyłowski, E. R., On Goldie and dual Goldie dimension, J. Pure Appl. Algebra, 31 (1984), 47-54

[11] Keskin Tütüncü, D. and Tribak, R., On dual Baer modules, Glasgow Math. J., 52 (2010), 261-269

[12] Rizvi, S. T. and Roman, C., Baer and quasi-Baer modules, Comm. Algebra, 32 (2004), 103-123

Department of Statistics-Forecasts-Mathematics

"BABEŞ-BOLYAI" UNIVERSITY

T. Mihali 58-60, 400591 Cluj-NAPOCA, ROMANiA

E-mail address: gabriela.olteanu@econ.ubbcluj.ro

Received: 24.03.2013; In revised form: 24.06.2013; Accepted: 25.06.2013

2010 Mathematics Subject Classification. 06A15, 16D10.

Key words and phrases. Galois connection, bounded modular lattice, (dual) Baer module. 